\title{
ENTREVISTA COM ADOLFO TANZI NETO: UMA PERSPECTIVA SÓCIO-HISTÓRICO-CULTURAL DO ENSINO HÍBRIDO E SUAS TECNOLOGIAS
}

\author{
Bruna Quartarolo Vargas ${ }^{1^{*}}$ \\ ${ }^{1}$ Universidade Federal do Rio de Janeiro, RJ, Brasil \\ Christine Nicolaides ${ }^{2 * *}$ \\ ${ }^{2}$ UNISINOS, São Leopoldo, RS, Brasil
}

Diante de um contexto de pandemia por conta do vírus da COVID-19, cujos efeitos avassaladores assolam não somente o Brasil, mas toda a humanidade, não apenas na área da saúde, mas também na educação, acreditamos que reflexões como as trazidas nesta entrevista por Adolfo Tanzi Neto, pesquisador na área da Teoria Sócio-histórico-cultural, podem fomentar possíveis caminhos para enfrentar os desafios que se apresentam e que se apresentarão em nossa sociedade em sua(s) nova(s) configuração(ões) nos próximos tempos. Configurações essas que vão desde a estrutura da sociedade como um todo, até suas relações de poder e interações. Este pode ser também um momento único na história da humanidade, com potencial de servir como espaço de transformação social e de diálogo entre diferentes grupos que historicamente não interagiam, mas que, pela gravidade da situação pela qual passamos, nos obriga a ouvir aquele(s) que pensa $(\mathrm{m})$ diferente de nós para juntos encontrarmos formas de garantir a sobrevivência da raça humana.

Nesse sentido, é preciso lembrar que não vivemos em um mundo estático e imutável, pré-configurado, mas repleto de oportunidades para mudanças, adaptações e transformações em todas suas instâncias. Assim, podemos encarar o momento de crise também como uma oportunidade para uma transformação social ativista da agência humana em relação ao seu espaço no mundo e nas relações com o outro, como bem observado por Stetsenko (2017). Nas palavras

\footnotetext{
* Mestra em Linguística Aplicada pela Universidade Federal do Rio Grande do Norte (UFRN) e Doutoranda do Programa de Pós-Graduação Interdisciplinar em Linguística Aplicada (PIGPLA) da Universidade Federal do Rio de Janeiro (UFRJ). Professora de Língua Inglesa do Colégio de Aplicação João XXIII da Universidade Federal de Juiz de Fora (UFJF). E-mail: brunaquartarolo@letras.ufrj.br / bruna.quartarolo@uff.br OCRID: https://orcid.org/0000-0003-0373-3130.

** Doutora em Letras pela Universidade Federal do Rio Grande do Sul. Professora pesquisadora do Programa Interdisciplinar de Pós-Graduação em Linguística Aplicada (PIPGLA) da Universidade Federal do Rio de Janeiro (UFRJ) e do Programa Pós-Graduação em Linguística Aplicada da Universidade do Vale do Rio dos Sinos. E-mail: christine.nicolaides@gmail.com ORCID: https://orcid.org/0000-0003-0167-3592.
} 
da autora, vivemos em um mundo "constantemente criado e recriado, inventado e reinventado, mudado e transformado, e então - realizado por e através da agência humana que é esse processo mundial de contribuir para as mudanças sociais que levam o mundo adiante"1 (STETSENKO, 2017, p. 206).

Desta forma, considerando as profundas transformações pelas quais a sociedade e a educação vêm passando, consideramos importante explorarmos o tema ensino híbrido, pela perspectiva da Teoria Sócio-Histórico Cultural. Para tanto, apresentamos o professor de inglês Adolfo Tanzi Neto, atualmente chefe do Departamento de Línguas Anglo-Germânicas da Faculdade de Letras da Universidade Federal do Rio de Janeiro (UFRJ) e pesquisador do Programa de Pós-Graduação Interdisciplinar em Linguística Aplicada (PIPGLA-UFRJ). Tratase de um dos autores do livro Ensino híbrido: personalização e tecnologia na educação (BACICH; TANZI NETO; TREVISANI, 2015), que vem contribuindo de forma profícua acerca do tema.

O pesquisador lidera o Núcleo de Estudos e Pesquisas da Escola Vygotsky em Linguística Aplicada (NUVYLA/CNPq), sendo coordenador regional e secretário global da ISCAR (The International Society of Cultural-Historical Activity Research), e vem realizando pesquisas sobre o discurso e as práticas sociais relacionadas ao desenvolvimento humano. Outros temas que interessam o pesquisador dizem respeito ao ativismo social, mobilidade linguística, mudança e justiça social, identidade e agência com base nas epistemologias críticas e dialéticas da Teoria Sócio-Histórico-Cultural.

Eis, então, a entrevista feita por Bruna Vargas, (doutoranda do Programa de Pós-Graduação Interdisciplinar em Linguística Aplicada da Universidade Federal do Rio de Janeiro e professora de Língua Inglesa do Colégio de Aplicação João XXIII da Universidade Federal de Juiz de Fora), e por Christine Nicolaides, professora pesquisadora do Programa Interdisciplinar de Pós-Graduação em Linguística Aplicada da Universidade Federal do Rio de Janeiro e do Programa Pós-Graduação em Linguística Aplicada da Universidade do Vale do Rio dos Sinos.

Entrevistadoras: Professor, o que você entende por recursos digitais e como os utiliza ao planejar e realizar sua prática pedagógica? Que efeitos podem ter nas relações entre docentes e discentes, em contextos superdiversos?

Adolfo Tanzi Neto: Para Vertovec (2007, apud TANZI NETO; OLIVEIRA, 2018, p. 49), "termos como modernidade tardia, condição pós-moderna, superdiversidade, entre outros, surgiram para refletir sobre as diferentes condições que caracterizam a formação das sociedades contemporâneas, as variadas origens, conectadas de modo transnacional e influenciadas pelos impactos das tecnologias de informação e comunicação, principalmente as digitais". Nesse sentido, "a necessidade de tentar compreender esses processos nos obrigou a pensar em como noções relativas ao tempo, espaço, fronteiras apresentam marcas de rupturas que afetam diretamente a nossa constituição identitária, linguística e cultural" (TANZI NETO, OLIVEIRA, 2018, p. 48). É 
essencial repensarmos os usos desses recursos para novas práticas de letramento, partindo de uma visão mais ampla, voltada para os "multiletramentos", que estão sempre interconectados às sociedades em que operam e ao papel das pessoas na sociedade em que vivemos. Tenho discutido em diferentes trabalhos o conceito de forma arquitetônica de Bakhtin, aplicado ao estudo de design de ambientes virtuais de aprendizagem ou até mesmo para refletirmos sobre o nosso plano/ design pedagógico. Nesse conceito de arquitetônica, Bakhtin (2010 [1924]) busca entender a sistematização científica do conhecimento, segundo a qual o centro de compreensão deve estar no processo de formação de totalidades, de uma "articulação dotada de sentidos, em vez de ligação ou justaposição mecânica das partes constituintes" (SOBRAL, 2008, p.13). Para Bakhtin, a forma arquitetônica é a construção ou estruturação que une e integra o material, a forma e o conteúdo. Em sua visão, a forma arquitetônica nos permite sempre perguntar "quem o produziu, para quem e em que circunstâncias" (BAKHTIN (2010 [1924])). Brait e Pistori (2012) complementam esse argumento discutindo que, para Bakhtin, o texto/enunciado não deve ser visto somente por sua forma externa apenas autônoma, mas por suas "condições concretas de vida, suas interdependências, suas relações, suas posições dialógicas e valorativas" (BRAIT; PISTORI, 2012, p.378), ou seja, por sua forma arquitetônica de realização (TANZI NETO, 2017; TANZI NETO; LESSA, 2014). Essa ideia nos possibilita olhar para esses ambientes ou recursos de aprendizagem sob a perspectiva da concepção, idealização e forma. Por exemplo, em uma sala de aula que, com a sua forma arquitetônica de realização (ergonomia), permite uma composição específica de organização de carteiras, estrutura do espaço, lousa, mural, etc.; e que propicia um modo singular de interação de um para muitos (centrado no professor), essa ergonomia/arquitetônica permite que certos gêneros discursivos nela se encaixem e outros não. $\mathrm{O}$ mesmo podemos observar em ambientes virtuais ou em outros recursos tecnológicos, em que o design da ferramenta pode propiciar uma abertura ou não para que diferentes modos de linguagem sejam praticados, relações de tempo e espaço (e poder), interação aluno/conhecimento, usos de diferentes semioses etc. Nesse sentido, ao refletir sobre essa composição arquitetônica, o docente repensa o seu papel nesse processo e o que busca propor para os seus alunos. Se considerarmos o momento atual, no qual cada vez mais diferentes encontros, por meios tecnológicos, com a língua, nos levam a diferentes níveis de conhecimento/reconhecimento linguístico travestidos em repertórios linguísticos superdiversos, entendemos a importância das contribuições da teoria da multimodalidade na educação contemporânea. Esse argumento se justifica na medida em que partimos do pressuposto de que apenas a escrita (com papel e caneta) não é mais suficiente para entendermos as manifestações discursivas do mundo moderno. Sendo assim, a urgência de se olhar para os diferentes usos do som, da imagem, do vídeo, mas não como mera ilustração e, sim, na composição linguística advinda da conjunção de modos superdiversos de linguagem para uma representação, ou seja, de modo a propor o reconhecimento e a percepção de uma miríade de repertórios linguísticos que estão agindo no mundo em formas 
complementares e contraditórias, que estão interligadas não apenas sob um espaço-tempo determinado, mas também com esses sujeitos. Para Blommaert, um autor que tenho lido já há algum tempo, esses repertórios superdiversos são ideologicamente carregados de características semióticas; de identidade e valores implícitos de poder, configuradas historicamente, atribuídas de gênero, posição semiótica, manipulação e identidade. Para tanto, é extremamente importante no sentido de dar circulação a uma prática multiletrada que ofereça uma educação linguística sob a égide do que estamos discutindo aqui - daí a necessidade de se averiguar não só se o design de recursos e ferramentas tecnológicas educacionais permite o uso e entendimento desses diferentes modos/repertórios de linguagem do mundo contemporâneo, mas também se o design pedagógico proposto pelo docente oferece uma unidade de ensino-aprendizagem que engaje criticamente os alunos a contribuir, colaborar e co-criar o mundo, nas palavras de Paulo Freire, em uma nova narrativa, em uma nova visão de mundo. Precisamos sair da escola marcada pelos gêneros e letramentos escolares convencionais de ensino para uma escola social de ativismo transformador que propicie diferentes modos de interação com a aprendizagem, com o conhecimento, que se aproxime da realidade vivida pelo cidadão contemporâneo e de seus novos modos de significação linguística. Essa discussão merece estar sempre em pauta nos espaços escolares, uma vez que passamos por incertezas trazidas pela globalização em que os sujeitos se engajam linguisticamente em uma ampla variedade de grupos, redes e comunidades, onde o próprio eu e a identidade são formados/transformados através dos encontros globais (formais e informais) que constantemente são afetados pelas rápidas mudanças sociais, econômicas e políticas.

Entrevistadoras: Diante das modificações pelas quais os processos de ensinoaprendizagem vêm passando devido à pandemia da Covid-19, pensar em recursos digitais para o ensino-aprendizagem é, mais do que nunca, uma tarefa fundamental. Que conceitos teóricos você utilizaria para embasar tal reflexão?

Adolfo Tanzi Neto: Neste momento, mais do que nunca, precisamos discutir o hibridismo de diferentes metodologias de trabalho e não somente de recursos tecnológicos. Em 2015 lancei, em parceria com mais dois colegas, o livro Ensino Híbrido: personalização e tecnologia na educação. Naquele momento, pouco era o interesse sobre os usos dos espaços presenciais em parceria com os espaços virtuais. Entretanto, com a pandemia, tivemos que repensar a nossa práxis escolar. Ensino híbrido é a bola da vez, mas não podemos esquecer, como já mencionei, que a tecnologia digital não resolverá o problema das mazelas educacionais do nosso país. O que sempre proponho é o exercício de pensarmos o que está por trás dos usos de tecnologias digitais, ou seja, se tivermos um objetivo claro e que propicie um novo olhar sobre os espaços educacionais, já estamos num movimento de transformação. A nossa discussão naquele momento, em 2015, centrava-se no papel do professor e do aluno em sala. Uma proposta de descentralização do papel do professor e de mais ação do lado do 
alunado, nada de novo no campo educacional do país. Infelizmente, ainda hoje, o que observamos em muitas escolas e aulas é a manutenção diariamente de aulas expositivas e de relações pouco simétricas entre aluno e professor. Sendo assim, mesmo tendo o termo ensino híbrido em voga no Brasil, o que temos visto é apenas uma transposição didática do presencial para o digital, como fizemos com a lousa, para o retroprojetor, para o projetor e agora para a sala de aula digital. A relação aluno/conhecimento ainda se concentra no professor em aulas expositivas e de conhecimento transmitido de forma verbal. Se quisermos aqui também retomar o conceito de arquitetônica/design temos a escola 1.0 nas relações de poder e controle, a escola hierárquica tendo o professor como único detentor do conhecimento. Como escola 1.0, me refiro à mentalidade 1, considerando uma definição proposta por Lankshear e Knobel (2007), na qual o mundo é centrado e hierárquico e a produção baseia-se na infraestrutura e em unidades ou centros (compartimentos). A especialidade e autoridade estão "localizadas" nos indivíduos e instituições. Já a escola 2.0, ou seja, na mentalidade 2, proposta pelos mesmos autores (LANKSHEAR; KNOBEL, 2007), a partir da qual a lógica do mundo é descentrada e o foco recai na participação contínua, as autoridades são distribuídas e coletivas num espaço mais aberto, fluído e colaborativo. A pandemia da Covid-19 nos fez ocupar diferentes espaços para ensinar e aprender. Essa ocupação que precisa ser repensada para não ser apenas uma transposição didática do presencial para o digital. Para isso, o design pedagógico necessita contemplar as questões que estamos discutindo aqui. $\mathrm{Na}$ época do lançamento do livro Ensino híbrido: personalização e tecnologia na educação, falávamos sobre o uso de estações para ocupar esse espaço de forma menos hierárquica. Hoje tenho debatido a questão de como essa perspectiva ficou apenas como um espaço cognitivista de tarefas a serem cumpridas pelos alunos. Nesse sentido, tenho proposto a discussão sobre "Comunidades de Aprendizagem"2", numa perspectiva da Teoria Sócio-histórico-Cultural, para o ensino-aprendizagem como processos de zonas proximais de desenvolvimento, agência (radical/ transformadora), aprendizagem como atividade social, mediação, entre outros. Assim, uma sala presencial ou virtual precisa oferecer diferentes "Comunidades de Aprendizagem”, que propiciem novos espaços de interação, colaboração, cocriação, desenvolvimento de relações interpessoais, autonomia, etc. Num sentido mais amplo, propiciar comunidades de interações/produções humanas que transformam, alteram, criam as suas relações com o conhecimento. Para tanto, vamos para além da sequência de atividades, mas de estações/comunidades de aprendizagem que ofereçam, no seu design/forma arquitetônica, atividades que os participantes discutam, criem, elaborem, se transformem e que a relação com o conhecimento venha por outros espaços/participantes de forma mais exploratória e não somente via professor verbalizado, transmissivo. Esse quase retorno das aulas, em meio à pandemia, tem colocado uma grande responsabilidade na vida dos professores, com classes mistas com alunos presenciais e remotos. Entretanto, tenho debatido que, se não entendermos a sala como única, mesmo tendo diferentes comunidades de aprendizagem como falamos aqui, o professor 
dará várias aulas, para quem está em casa e para quem está na sala presencial. Mas se oferecermos um design pedagógico que contemple o grupo (presencial/ remoto) como uma unidade de trabalho, propiciando diferentes interações com os alunos presenciais e remotos, poderemos sair dessa compartilhando trabalhos e desenvolvendo mais autonomia dos nossos alunos. Tenho plena consciência de que precisamos caminhar muito com a questão da autonomia, para o que estamos discutindo, mas, se não buscarmos espaços para que isso se construa, continuaremos na escola do passado.

Entrevistadoras: As ferramentas digitais no Ensino Remoto Emergencial podem representar uma saída ou uma cilada, se considerarmos, por exemplo, as dificuldades sócio econômicas de grande parte de alunas e alunos brasileiros. Como podemos buscar equalizar isso e ao mesmo tempo promover momentos de aprendizagem significativa?

Adolfo Tanzi Neto: As ferramentas digitais por si só não resolvem o problema da educação, como já aqui mencionado. Toda escola, seja ela com ou sem recursos econômicos, que busca, por meio das tecnologias digitais, a solução para seus processos de ensino-aprendizagem, está entrando em uma grande cilada. As discussões formativas, os projetos institucionais e até mesmo os Projetos Político-Pedagógicos de cada escola devem centrar-se nas potencialidades que esses recursos podem oferecer ou não. Ter um tablet ou um chromebook, em sala de aula, apenas para ler pdfs ou textos lineares, não resolve. O livro impresso dá conta disso. É preciso buscar essas ferramentas para oferecer novos multiletramentos, ou seja, novas relações do aluno com o conhecimento, aí sim podemos tirar proveito desses recursos. Entretanto, como mencionei, a discussão deve estar um passo atrás, a pandemia não só acirrou as diferenças socioeconômicas, mas mostrou, em muitos casos, que a transposição didática foi exatamente do mesmo espaço presencial, hierárquico, expositivo de transmissão verbal, agora transvestido de uma nova tecnologia, como a Google sala, Google Meet, Zoom, etc. Se colocarmos todos os fatores na ponta do lápis, ninguém evoluiu muito nessa pandemia, mesmo nas escolas que tiveram todos os recursos tecnológicos, poucos foram os resultados positivos de aprendizagem. Quando converso com colegas de diferentes instituições de ensino fundamental, médio e superior, a resposta é a mesma: alunos que não abrem a câmera, professores falando para as paredes e muito pouca interação com o conhecimento. O mesmo tem acontecido com as escolas que implementaram as vídeo aulas, por meio de canais televisivos ou do rádio em cidades mais longínquas do Brasil. Todos saímos defasados dessa pandemia porque não conseguimos repensar o status quo da escola, quisemos ainda ser os detentores do conhecimento, mas agora sem estarmos com os alunos presos na nossa frente. Conseguimos observar o abismo em que a escola se encontra nessa relação aluno/professor/conhecimento. A aprendizagem significativa só se dá se houver uma intrínseca relação com a prática social, como já discutido por diferentes teóricos, e ela é pervasiva, ou 
seja, é social, emocional, cognitiva, nos afeta por diferentes perspectivas. Mesmo na pandemia, não conseguimos olhar o entorno dos nossos alunos como espaço de ensino-aprendizagem, todos os formatos, dos mais exitosos aos mais básicos, foram da forma de transmissão de conhecimento com pouco envolvimento do aluno no processo de ensino-aprendizagem. Essa discussão não isenta os governantes deste país de oferecer tecnologias digitais para todas as escolas públicas, acesso a uma internet de qualidade e todos os recursos tecnológicos disponíveis no mercado para os nossos brasileiros em processo de formação, mas também não nos isenta de pensar em como trabalhar com esses recursos, sejam eles muitos ou poucos. Talvez não tenha dado a resposta na direção que buscavam, mas é que tenho insistido em darmos um passo atrás - se vamos trabalhar com os textos em pdf, a minha discussão está em como colocar esse aluno no centro do processo de ensino-aprendizagem, e quando digo isso, não é sozinho, mas em colaboração com os outros integrantes do seu espaço escolar. Isso independe de recursos de ponta, mas, sim, de um design pedagógico que contemple a voz do aluno, a interação com diferentes participantes, a colaboração, a co-criação, e a propiciação de novas relações com o conhecimento, menos hierárquicas, mais simétricas e mais significativas, como já mencionado. O que precisamos com urgência é de uma escola que ofereça processos de ensino-aprendizagem conectados, compartilhados por diferentes contextos sócio-histórico-culturais, nos quais os alunos possam construir, analisar, avaliar, criticar, reconstruir, criar/ transformar coletivamente novas realidades.

Entrevistadoras: Se consideramos modelos escolares descritos como inspiradores em sua pesquisa de doutorado em parceria com a Universidade de Oxford, como por exemplo os da Escola da Ponte (em São Tomé de Negrelos, Santo Tirso, Portugal) e o do Projeto Ginásio Experimental de Novas Tecnologias Educacionais - GENTE, na Comunidade da Rocinha, Rio de Janeiro, Brasil), você acredita que a pandemia da Covid 19 adiantou uma transformação que iria ocorrer, mais cedo ou mais tarde, nas relações de ensino-aprendizagem?

Adolfo Tanzi Neto: Não sei se adiantou, mas trouxe reflexões fundamentais para o contexto educacional. Tenho reforçado em palestras, lives e bate-papos com diferentes secretarias educacionais que as câmeras e microfones fechados dos alunos são um sinal de que a nossa educação está muito distante do contexto social do nosso alunado. $\mathrm{Na}$ verdade, essas câmeras e microfones sempre estiveram fechadas na sala de aula presencial, mas a aula sempre seguiu sem muito querer saber as opiniões dos seus ouvintes. Inovar no contexto escolar não é uma discussão nova, mas a questão está bem antes de pensarmos num design escolar mais robusto. Isso foi possível observar quando estivemos no grupo de pesquisa "Design Matters?"3, na Universidade de Oxford, no departamento de educação, que buscava entender por meio de escolas "inovadoras" como se dava a ocupação, a percepção e o engajamento dos envolvidos nesse nosso espaço social escolar. Naquela época, pudemos verificar que somente a inovação do espaço 
escolar não é suficiente, se não houver um projeto político pedagógico muito bem delineado, construído a várias mãos com a participação de professores, alunos, responsáveis e toda a comunidade do seu entorno. Nessa pesquisa, parte de minha tese, citada aqui, observei em escolas dentro de comunidades do Rio de Janeiro que a inovação, mesmo em um prédio de arquitetura mais antiga, sem muitos recursos tecnológicos digitais de ponta, é possível. A inovação que todos buscam em diferentes partes do mundo é a da nossa relação com o conhecimento, menos transmissiva, hierárquica, expositiva, mais colaborativa, exploratória, simétrica e participativa, como já exposto.

Entrevistadoras: Para esta pergunta, tomamos emprestada uma citação de seu livro "Arquitetônica Social Escolar", no qual você afirma ser a escola "um espaço social de práticas situadas, que busca o desenvolvimento da mente para o aprendizado, considerando que o ensino-aprendizagem se estabelece pelo envolvimento de seus participantes em cenários sociocultural, histórica e institucionalmente situados". Como você compreende essa relação diante do contexto de Ensino Remoto Emergencial?

Adolfo Tanzi Neto: Nesse livro, buscamos entender a "ciência do espaço" em uma perspectiva lógico-epistemológica sobre os níveis de inter-relações que se estabelecem em um espaço de práticas sociais, saindo das discussões apenas da estrutura, de visões simplistas, fragmentadas e tipificadas de contextos, mas permanecendo no campo de como sujeitos produzem um espaço social. Nosso objetivo geral era entender como é produzido um todo arquitetônico escolar, em que a materialização de práticas de linguagem se dá à medida que essas práticas se realizam, se materializam, tornam-se reais, concretas e impregnadas de significados. Na perspectiva bakhtiniana, esse espaço pode ser visto em um todo arquitetônico, em que se encontram as formas de linguagem, uma massa verbovisual de interações, no seu aspecto de vida particular, social e histórica. O todo arquitetônico de um espaço corresponde aos campos de atividades humanas. Em consonância com as formas de linguagem, podemos trazer Vygotsky, em sua Teoria Sócio-Histórico-Cultural, para entender como a consciência humana está intrinsecamente ligada ao uso de artefatos mediadores, que estão ligados às atividades humanas. Nesse sentido, precisamos entender como vamos fazer essa ocupação do espaço digital ou dos diferentes espaços digitais no período remoto. Em outras palavras, que formas de linguagem, relações de poder, ou seja, que artefatos mediadores trabalharemos nesse espaço para que o seu todo arquitetônico ofereça o que estamos discutindo aqui para a educação brasileira. A discussão sobre "Arquitetônica Social Escolar" nos propicia repensar os espaços sociais escolares, uma vez que formas e hábitos que cercam os nossos jovens nos contextos escolares os guiam, os instruem, os moldam. E, se quisermos realmente que esses jovens sejam futuros cidadãos críticos em nossa sociedade, precisamos oferecer um espaço social que privilegie as vozes, as identidades multifacetadas, os posicionamentos sociais e os contextos diversos: familiares, periféricos e de 
comunidade. Acredito também que essa discussão sobre uma "Arquitetônica Social Escolar" pode oferecer ferramentas para professores formadores, diretores e coordenadores de escolas que queiram repensar a dinâmica do seu contexto social escolar.

Entrevistadoras: No ano de 2020, juntamente com os professores Fernanda Liberali e Manolis Dafermos, você lançou o livro Revisiting Vygotsky for Social Change: Bringing Together Theory and Practice (Revisitando Vygotsky para Transformação Social: Unindo Teoria e Prática), cuja temática nos leva a refletir profundamente sobre a urgente necessidade de prezarmos por uma práxis que promova a transformação e o desenvolvimento social. Levando em consideração uma citação retirada do capítulo final desse livro, escrito por você com a colaboração dos renomados pesquisadores Michalis Kontopodis e Manolis Dafermos, na qual afirmam que um momento de crise pode ser compreendido como "um ponto de virada em que uma decisão difícil ou importante deve ser tomada" (KONTOPODIS et. al, 2020, p. 282), de que forma a transformação social pode ser pensada para uma aplicação pedagógica que possibilite potencializar a aprendizagem e o desenvolvimento de forma coletiva?

Adolfo Tanzi Neto: Vivemos em tempos de resistência e de incertezas trazidas pela globalização e como os sujeitos se envolvem em uma ampla variedade de grupos, redes e comunidades, nos quais as próprias identidades são formadas/ transformadas por meio de encontros globais formais e informais. Tais incertezas colocam uma questão bastante discutida no campo da educação, e já falada aqui, que é o desafio de passar de um ponto de vista da escola de transmissão do conhecimento, como um modelo bancário (depositando conhecimento), conforme criticado por Paulo Freire, para um projeto social escolar de transformação crítica e auto desenvolvimento dos alunos. Para Anna Stetsenko, esse caminho deve ser explorado na unidade ensino-aprendizagem como postura ativista transformadora. Sob essa ótica, os alunos são vistos como atores sociais que contribuem, colaboram e co-criam de forma atuante, como posto por ela, num mundo sempre muito instável, contestado e não finalizado. De acordo com Stetsenko (2014), a escola atual, baseada nas filosofias e teorias dominantes para o desenvolvimento e aprendizagem humana, tem efeitos danosos na sociedade, uma vez que perpetua a crise da desigualdade, mercantilização da ciência e da educação. Diante disso, conceituações e metodologias alternativas devem ser desenvolvidas para criar possibilidades de desenvolvimento humano e para uma educação que busque questionar o seu status quo, como exposto por ela, em diferentes ocasiões. Essa seria uma abordagem vital para o desenvolvimento das escolas brasileiras. Para a referida autora, essas concepções abordam a subjetividade humana e a agência para a mudança/justiça social e sustentam diferentes visões de mundo críticas sobre as causas econômicas e políticas sistêmicas e estruturais. Por todo o livro, buscamos revisitar Vygotsky para mudança social, como o próprio título sugere, e contribuir para diferentes áreas 
sobre a urgência em que vivemos para repensarmos o status quo da sociedade. Eu acredito que esse possa ser um caminho para transformar realidades. Tenho discutido e trabalhado com o conceito de agência no espaço escolar, uma agência para mudança, para justiça social, que pode ser entendida, como exposto por Fernanda Liberali e outros pesquisadores, como rupturas de padrões de ações pré-estabelecidas nos papéis dos sujeitos para tomar iniciativas para transformar realidades. Para Cecília Magalhães e Maria Otília Ninin, o desenvolvimento da agência envolve distinguir contradições para criar novas possibilidades de expansão e transformação de realidades. Considerando as condições que permeiam a realidade da escola pública brasileira, em que há todos os tipos de exclusão social, gênero, classe, necessidades especiais e raça em um contexto de crianças e adolescentes, cuja percepção é muito limitada no que diz respeito ao seu papel de atuação na mudança da realidade envolvente, a discussão de uma escola que promova a agência dos alunos para a mudança social/justiça no Brasil é fundamental.

Entrevista concedida em 11 de março de 2021, por meio eletrônico.

\section{Notas}

1. Todas as traduções neste trabalho são livres e de responsabilidade das autoras desta entrevista.

2. Conceito que está em construção, mas que busca refletir sobre a ocupação das salas de aulas por meio de diversas "comunidades de aprendizagem", se distanciando da perspectiva de estações rotacionais da proposta de Ensino Híbrido (tarefeira, conteudista) que trouxemos para o Brasil em 2012, para espaços que propiciem mais colaboração, autonomia e a construção de novas relações interpessoais e com o conhecimento. Para a discussão expandida sobre Ensino Híbrido ver a notícia do G1 - Ensino Híbrido: as dificuldades para o aprendizado com parte da turma online e a outra em sala de aula. Disponível em: https://g1.globo.com/ educacao/volta-as-aulas/noticia/2021/03/10/ensino-hibrido-as-dificuldadespara-o-aprendizado-com-parte-da-turma-on-line-e-a-outra-na-sala-de-aula. ghtml. Acesso em 24 maio de 2021. Sugerimos ainda a leitura de BACICH; TANZI NETO; TREVISANI (2015).

3. Fotos e Materiais analisados podem ser acessados pelo link da tese de Adolfo Tanzi Neto, em https://tede.pucsp.br/handle/handle/19527.

\section{Referências}

BACICH, L; TANZI NETO, A; TREVISANI; F. M. Ensino híbrido: personalização e tecnologia na educação. Porto Alegre: Penso, 2015.

BAKHTIN. M. Crítica da Arte e Estética Geral. In: BAKHTIN, M. Questóes de Literatura e de Estética: a teoria do romance. 6a ed. São Paulo: Hucitec, [1924]2010.

BLOMMAERT, J. Commentary: Superdiversity old and new. Language \& Communication, Vol. 44, Pages 82-88, 2015. Disponível em: https://doi. org/10.1016/j.langcom.2015.01.003. Acesso em 19/07/2021. 
BRAIT, B.; PISTORI, M. H. C. A produtividade do Conceito de Gênero em Bakhtin e o Círculo. Alfa, São Paulo. Vol. 56 (2), p.371-401, 2012. Disponível em: https:// www.scielo.br/j/alfa/a/6VGDTp93BHDqyWfKF5TsDpf/?format=pdf\&lang=pt. Acesso em 19/07/2021.

FREIRE, P. Pedagogia do oprimido. Rio de Janeiro: Paz e Terra, 1987.

KONTOPODIS, M; DAFERMOS, M; TANZI NETO, A. Instead of an epilogue. "We are on fire": Crisis as turning point, Vygotsky and social change. In: TANZI NETO, A; LIBERALI, F.; DAFERMOS, M. (Editores). Revisiting Vygotsky for social change: bringing together theory and practice. Peter Lang Publishing, Inc., New York, 2020.

LANKSHEAR, C.; KNOBEL, M. Sampling "the new" in new literacies. In: M. KNOBEL; C. LANKSHEAR (Eds.) A new literacies sampler: New literacies and digital epistemologies. New York: Peter Lang, 2007. Vol. 29, p. 1-24.

LIBERALI, F. C. Building agency for social change. In: TANZI NETO, A; LIBERALI, F.; DAFERMOS, M. (Editores). Revisiting Vygotsky for social change: bringing together Theory and Practice. Peter Lang Publishing, Inc., New York, 2020. 298 p.

NININ, M. O. G; MAGALHÃES, M. C. C. A linguagem da colaboração crítica no desenvolvimento da agência de professores de ensino médio em serviço. Alfa, São Paulo, v. 61, n.3, p.625-652, 2017. Disponível em: http://doi.org/10.1590/19815794-1711-7. Acesso em 19/07/2021.

STETSENKO, A. Transformative activist stance for education: Inventing the future in moving beyond the status quo. In: T. CORCORAN (Ed.). Psychology in Education: Critical Theory-Practice. Rotterdam, The Netherlands: Sense Publishers, 2014. Disponível em: https://www.researchgate.net/ publication/265079764_TRANSFROMATIVE_ACTIVIST_STANCE_FOR_ EDUCATION_The_challenge_of_inventing_the_future_in_moving_beyond_ the_status_quo_In_In_T_Corcoran_Ed_Psychology_in_Education_Critical_ TheoryPractice_pp_181-198_Rotter. Acesso em 17/07/2021.

The Transformative Mind: expanding Vygotsky's approach to development and education. New York, Cambridge University Press, 2016.

Transformative Activist Stance: Agency. In: STETSENKO, A. (Org.) The Transformative Mind: expanding Vygotsky's approach to development and education. Cambridge University Press: New York, 2017.

TANZI NETO, A. Arquitetônica social escolar: um estudo sócio, histórico e cultural sobre as relações de poder e controle nos espaços, artefatos e discursos. 2016. 362 f. Tese (Doutorado em Linguística Aplicada e Estudos da Linguagem) - Programa de Estudos Pós-Graduados em Linguística Aplicada e Estudos da Linguagem, Pontifícia Universidade Católica de São Paulo, São Paulo, 2016. Disponível em: https://tede.pucsp.br/handle/handle/19527. Acesso em 24 maio de 2021.

TANZI NETO, A. Arquitetônica social escolar: Vygotsky, Bakhtin e Bernstein, espaços, discursos, artefatos e suas relações de poder e controle. Campinas: Pontes editores, 2017.

TANZI NETO, A.; LESSA, A. B. C. T. Arquitetura de ambientes virtuais de aprendizagem sob a ótica dos estudos bakhtinianos. Bakhtiniana, Rev. Estud. Discurso [online]. 2014, vol.9, n.2, p.164-183. Disponível em: https://www. scielo.br/j/bak/a/pjmcgTb7rPmBkBdcHWhDczb/abstract/?lang=pt. Acesso em 19/07/2021.

TANZI NETO, A.; OLIVEIRA, G. C. de A. Translocalidade, repertórios e indexicalidade: efeitos constitutivos do discurso contemporâneo em espaços digitais superdiversos. Revista Intercâmbio, v. XXXVIII: 46-68, 2018. Disponível 
em: https://revistas.pucsp.br/intercambio/article/download/40962/27639. Acesso em 19/07/2021.

TANZI NETO, A; LIBERALI, F.; DAFERMOS, M. (Editores). Revisiting Vygotsky for social change: bringing together theory and practice. Peter Lang Publishing, Inc., New York, 2020.

VERTOVEC, S. "Superdiversity and its implications". Ethnic and racial studies, v. 30, n. 6: 1024-1054, 2007.

Recebido em: 14/03/2021

Aceito em: 17/05/2021 